\title{
Symposium
}

\section{Neurobiological Mechanisms of the Placebo Effect}

\author{
Fabrizio Benedetti, ${ }^{1}$ Helen S. Mayberg, ${ }^{2}$ Tor D. Wager, ${ }^{3}$ Christian S. Stohler, ${ }^{4}$ and Jon-Kar Zubieta ${ }^{5}$ \\ ${ }^{1}$ Department of Neuroscience, University of Turin Medical School, 10125 Turin, Italy, ${ }^{2}$ Department of Psychiatry and Behavioral Sciences, Emory \\ University, Atlanta, Georgia 30322, ${ }^{3}$ Department of Psychology, Columbia University, New York, New York 10027, ${ }^{4}$ School of Dentistry, University of \\ Maryland, Baltimore, Maryland 21201, and 5epartment of Psychiatry and Molecular and Behavioral Neuroscience Institute, The University of Michigan, \\ Ann Arbor, Michigan 48109
}

Key words: placebo; PET; fMRI; pain; stress; opioid receptors; Parkinson’s disease; depression; antidepressants; human

Any medical treatment is surrounded by a psychosocial context that affects the therapeutic outcome. If we want to study this psychosocial context, we need to eliminate the specific action of a therapy and to simulate a context that is similar in all respects to that of a real treatment. To do this, a sham treatment (the placebo) is given, but the patient believes it is effective and expects a clinical improvement. The placebo effect, or response, is the outcome after the sham treatment. Therefore, it is important to emphasize that the study of the placebo effect is the study of the psychosocial context around the patient.

The placebo effect is a psychobiological phenomenon that can be attributable to different mechanisms, including expectation of clinical improvement and pavlovian conditioning. Thus, we have to look for different mechanisms in different conditions, because there is not a single placebo effect but many. So far, most of the neurobiological mechanisms underlying this complex phenomenon have been studied in the field of pain and analgesia, although recent investigations have successfully been performed in the immune system, motor disorders, and depression. Overall, the placebo effect appears to be a very good model to understand how a complex mental activity, such as expectancy, interacts with different neuronal systems (Colloca and Benedetti, 2005; Finniss and Benedetti, 2005).

Recently, the placebo effect has reemerged in the public and scientific interest because of investigations of its biological substrates (de la Fuente-Fernandez et al., 2001; Mayberg et al., 2002; Petrovic et al., 2002; Lieberman et al., 2004; Wager et al., 2004; Colloca and Benedetti, 2005; Zubieta et al., 2005a). The public is interested in placebo effects because they promise increased selfcontrol; the existence of placebo effects suggests that we must broaden our conception of the limits of endogenous human capability. Scientists are interested in placebo responses because the effects of belief on human experience and behavior provide an entry point for studying internal control of affective, sensory, and

Received Aug. 16, 2005; revised Sept. 29, 2005; accepted 0ct. 3, 2005.

This work was supported by National Institutes of Health Grant R01 AT 001415 (J.-K.Z.), Italian Ministry of University and Research-Fondo per gli Investimenti della Ricerca di Base Grant RBNE01SZB (F.B.), National Institute of Mental Health Grant MH-49553, and a physician-initiated grant from Eli Lilly \& Company (H.S.M.), and by funding from the Mind, Brain, Body, and Health Initiative (T.D.W.). We thank the many collaborators and colleagues who have provided invaluable contributions to the work we describe here.

All authors contributed equally to this manuscript.

Correspondence should be addressed to Dr. Jon-Kar Zubieta, University of Michigan, Molecular and Behavioral Neuroscience Institute, 205 Zina Pitcher Place, Ann Arbor, MI 48109-0720. E-mail: zubieta@umich.edu. DOI:10.1523/JNEUROSCI.3458-05.2005

Copyright $\odot 2005$ Society for Neuroscience $\quad 0270-6474 / 05 / 2510390-13 \$ 15.00 / 0$ peripheral processes. The study of the placebo effect, at its core, is the study of how the context of beliefs and values shape brain processes related to perception and emotion and, ultimately, mental and physical health. The study of the placebo effect reflects a current neuroscientific thought that has as its central tenet the idea that "subjective" constructs such as expectation and value have identifiable physiological bases, and that these bases are powerful modulators of basic perceptual, motor, and internal homeostatic processes.

The study of the placebo effect also has immediate clinical and ethical implications, because the use of inactive (placebo) conditions in clinical trials when effective treatments are available has created an ethical controversy. However, it has been well documented that placebo effects can obscure those of active conditions, even for treatments that were eventually demonstrated to be effective. Thus, placebo effects may represent points of either strength or vulnerability for the expression and maintenance of various pathological states and their inherent therapeutic interventions.

\section{The pharmacological approach}

The neurobiology of the placebo effect was born in 1978, when it was shown that placebo analgesia could be blocked by the opioid antagonist naloxone, which indicates an involvement of endogenous opioids (Levine et al., 1978). By using this pharmacological approach with naloxone, several other studies have confirmed and extended this observation. For example, a placebo can reduce pain by both opioid and non-opioid mechanisms (Colloca and Benedetti, 2005) (Fig. 1). In the first case, placebo analgesia is typically blocked by the opioid antagonist naloxone, whereas in the second case it is not, depending on the procedure that is applied to induce the placebo analgesic response. In an experimental model of pain (Amanzio and Benedetti, 1999), the placebo response could be blocked by naloxone if it was induced by strong expectation cues, whereas if the expectation cues were reduced, it was insensitive to naloxone. In the same study, if the placebo response was obtained after exposure to opioid drugs, it was naloxone reversible, whereas if it was obtained after exposure to non-opioid drugs, it was naloxone insensitive. These data indicate that opioid and non-opioid mechanisms come into play under different circumstances. The placebo-activated endogenous opioid systems have been shown to have a somatotopic organization, because local naloxone-reversible placebo re- 


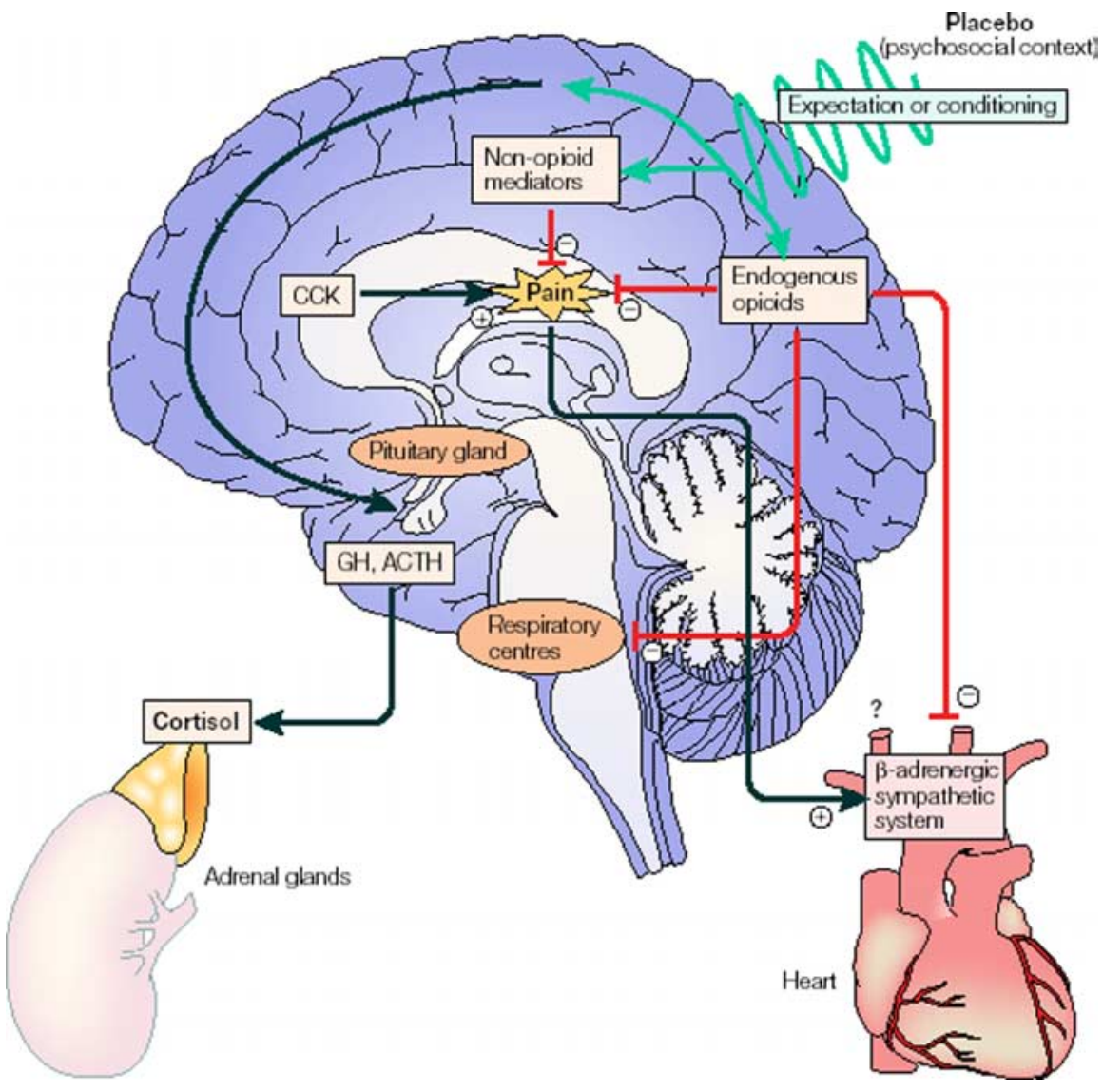

Figure 1. Events that might take place in the brain after placebo administration. Placebo administration (psychosocial context) might reduce pain through opioid and/or non-opioid mechanisms via expectations and/or conditioning mechanisms. The respiratory centers may also be inhibited by endogenous opioids. The $\beta$-adrenergic sympathetic system of the heart may also be inhibited during placebo analgesia, although the mechanism is not known (reduction of the pain itself and/or direct action of endogenous opioids). CCK antagonizes the effects of endogenous opioids, thereby reducing the placebo response. Placebos can also act on 5-HT-dependent hormone secretion, on both the pituitary and adrenal glands, thereby mimicking the effect of the analgesic drug sumatriptan. From Colloca and Benedetti (2005).

sponses can be obtained in different parts of the body (Benedetti et al., 1999b).

On the basis of the anti-opioid action of cholecystokinin (CCK) (Benedetti, 1997), the CCK antagonist proglumide was found to enhance placebo analgesia through the potentiation of the placebo-activated opioid systems (Benedetti et al., 1995). Thus, the placebo analgesic response appears to result from a balance between endogenous opioids and endogenous CCK (Fig. 1). In one additional study in chronic pain patients, it was found that placebo responders showed higher concentration of endorphins in the CSF than placebo nonresponders (Lipman et al., 1990).

The placebo-activated endogenous opioids have also been shown to produce respiratory depression, a typical side effect of opioids. In fact, after repeated administrations of the opioid buprenorphine in the postoperative phase, which induces mild respiratory depression, a placebo is able to mimic the same respiratory depressant response, an effect that can be totally blocked by naloxone (Benedetti et al., 1999a). Therefore, not only do placebo-activated opioid systems act on pain mechanisms, but they act on the respiratory centers as well (Fig. 1). A recent study, in which the sympathetic control of the heart was analyzed during placebo analgesia, found that placebo analgesia was accompanied by a reduced heart rate and a decreased $\beta$-adrenergic response, an effect that was reversed by naloxone, which indicates that opioid- mediated placebo analgesia also affects the cardiovascular system (Pollo et al., 2003) (Fig. 1).

In another recent study, some of the circumstances in which expectation and conditioning are involved have been suggested. In this study (Benedetti et al., 2003), the effects of opposing verbal suggestions on experimental ischemic arm pain in healthy volunteers and on motor performance in parkinsonian patients were analyzed. It was found that verbally induced expectations of analgesia/hyperalgesia and of motor improvement/worsening antagonized completely the effects of a conditioning procedure. In contrast, it was found that expectations of increase/ decrease of growth hormone $(\mathrm{GH})$ and cortisol did not have any effect on the secretion of these hormones. However, if a preconditioning was performed with sumatriptan, a $5-\mathrm{HT}_{1 \mathrm{~B} / 1 \mathrm{D}}$ agonist that stimulates GH and inhibits cortisol secretion, a significant increase of GH and decrease of cortisol plasma concentrations were found after placebo administration, although opposite verbal suggestions were given (Fig. 1). These findings suggest that expectations have no effect on hormonal secretion, although they affect pain and motor performance. This also provides some evidence that placebo responses are mediated by conditioning when unconscious physiological functions, such as hormonal secretion, are involved, whereas they are mediated by expectation when conscious physiological processes, such as pain and motor performance, come into play, although a conditioning procedure is performed. Thus, the placebo effect seems to be a phenomenon that can be learned either consciously or unconsciously, depending on the system that is involved (e.g., pain or hormone secretion).

The role of conditioning in the placebo effect is also shown by studies on the immune responses (Ader, 2003). For example, repeated associations between cyclosporin A (unconditioned stimulus) and a flavored drink (conditioned stimulus) induced conditioned immunosuppression in humans, in which the flavored drink alone produced a suppression of the immune functions, as assessed by means of interleukin-2 (IL-2) and interferon- $\gamma($ IFN- $\gamma$ ) mRNA expression, in vitro release of IL-2 and IFN- $\gamma$, as well as lymphocyte proliferation (Goebel et al., 2002). This study supports a conditioning mechanism in immunosuppressive placebo responses and is in keeping with the effects of sumatriptan conditioning on $\mathrm{GH}$ and cortisol secretion (Benedetti et al., 2003).

It is worth pointing out that these placebo mechanisms have an important influence on the therapeutic outcome, and indeed they enhance the specific effect of a treatment. These additive effects have been demonstrated recently by studies that assessed treatment efficacy after the hidden administration of different therapies. In fact, the open administration of a treatment, in which the subject knows what is going on and expects an outcome, is more effective than a hidden one, in which the subject 
does not know that any therapy is being given and thus does not expect anything (Colloca et al., 2004). Likewise, the expected administration of a drug has a more powerful effect on brain metabolism than the unexpected administration (Volkow et al., 2003). These findings show that drug effects are reduced if expectations are absent and underscore how the knowledge about a treatment affects the therapeutic outcome.

\section{The placebo effect in motor control: studies in Parkinson's disease}

Recently, Parkinson's disease has emerged as an interesting model to understand the neurobiological mechanisms of the placebo response. In this case, patients are given an inert substance (the placebo) and are told that it is an antiparkinsonian drug that produces an improvement in their motor performance. A recent study used positron emission tomography (PET) to assess the competition between endogenous dopamine and $\left[{ }^{11} \mathrm{C}\right]$ raclopride for $\mathrm{D}_{2} / \mathrm{D}_{3}$ receptors, a method that allows identification of endogenous dopamine release (de la Fuente-Fernandez et al., 2001). This study found that placebo-induced expectation of motor improvement activates endogenous dopamine in the striatum of parkinsonian patients. In addition, it has been found that expectations of poor versus good motor performance modulate the therapeutic effect of subthalamic nucleus stimulation in parkinsonian patients who had undergone chronic implantation of electrodes for deep brain stimulation (DBS). In fact, by analyzing the effect of subthalamic stimulation on the velocity of movement of the right-hand, the hand movement was found to be faster when the patients expected a good motor performance. These effects occurred within minutes, suggesting that expectations induce neural changes very quickly (Pollo et al., 2002).

The strong placebo responses in Parkinson's disease and the possibility to study parkinsonian patients who are implanted with electrodes for deep brain stimulation has been exploited recently to record from single neurons after placebo administration (Benedetti et al., 2004). In this study, the activity from single neurons in the subthalamic nucleus was recorded before and after placebo administration to see whether neuronal changes were linked to the clinical placebo response. The placebo consisted of a saline solution that was given to patients along with the suggestion that it was an antiparkinsonian drug. This procedure was performed intraoperatively after preoperative pharmacological conditioning with apomorphine, a powerful antiparkinsonian drug. It was found that the placebo responders showed a significant decrease of neuronal discharge and a reduction of bursting activity of subthalamic neurons, whereas the placebo nonresponders did not. Remarkably, as shown in Figure 2 for two representative patients (a placebo responder and a nonresponder), there was a nice correlation between the subjective reports of the patients, the clinical assessment of the neurologist, and the electrical activity of single neurons.

Thus, Parkinson's disease offers us an exciting and innovative model to understand the intricate relationship between expectations and neuronal systems. In particular, the possibility of recording from single neurons offers us the chance to identify the neuronal changes that take place in the basal ganglia circuitry during the placebo response.

\section{Endogenous opioid mechanisms in placebo analgesia: neuroimaging studies}

As described above, substantial evidence implicates the endogenous opioid system in the mediation of placebo effects under conditions of expectation of analgesia. During both clinical and $\mathbf{a}$

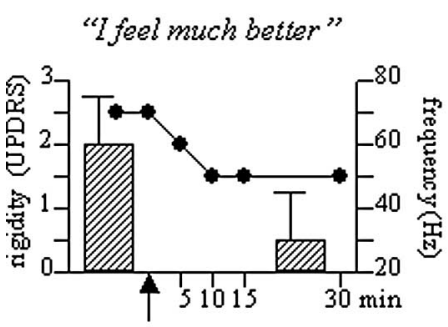

b

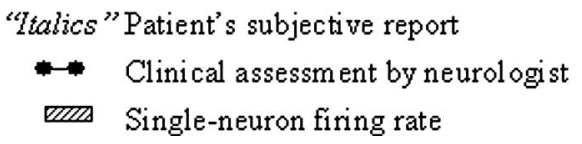

Figure 2. Correlation between subjective report (italics), arm rigidity (black circles), and subthalamic nucleus neuronal frequency discharge (bars) in two representative Parkinson's disease patients. The black arrow on the abscissa indicates placebo administration. Note the subjective sensation of well-being, along with arm rigidity decrease and neuronal firing rate reduction, in the placebo responder $(\boldsymbol{a})$ but not in the nonresponder $(\boldsymbol{b})$. Modified from Benedetti et al. (2004).

experimentally induced pain, placebo administration with expectation of analgesia has been associated with reductions in pain ratings that were reversed by either the open or hidden administration of naloxone (i.e., they were mediated by the activation of pain-suppressive endogenous opioid neurotransmission) (Gracely et al., 1983; Grevert et al., 1983; Levine and Gordon, 1984; Benedetti, 1996; Amanzio and Benedetti, 1999). Nonopioid mechanisms have also been described, particularly in the context of previous preconditioning with non-opioid agents (Amanzio and Benedetti, 1999).

In an initial examination of the neuronal circuitry implicated in these mechanisms, Petrovic et al. (2002) described a coincidence of increases in regional cerebral blood flow (CBF) by the systemic administration of a $\mu$-opioid receptor agonist, remifentanil, and placebo with expectation of analgesia in the rostral anterior cingulate cortex. Furthermore, individuals who were placebo responders showed more pronounced rostral anterior cingulate regional blood flow responses to remifentanil. These data then suggested the presence of variations in the responses of the $\mu$-opioid receptor system as a function of placebo response, localized in the rostral anterior cingulate.

Regarding the circuitry implicated in placebo analgesia (and as described in more detail below in Functional neuroanatomy of placebo analgesia), Wager et al. (2004) used functional magnetic resonance imaging (fMRI) to indirectly measure neuronal activity during the administration of a placebo with expectation of analgesia. Placebo administration was associated with reductions in the activity of pain-responsive regions while subjects underwent a painful heat stimulus. The regions involved included the rostral anterior cingulate, the insular cortex, and the thalamus. This study used an expectancy manipulation to elicit a placebo response, which enhances belief in the placebo. This procedure does not involve classical conditioning per se (because there is no active unconditioned stimulus), which has been associated with non-opioid-mediated analgesic mechanisms (Amanzio and Benedetti, 1999). Although the methodology used does not examine the neurochemical mechanisms inducing the placebo analgesic effect, the regions implicated do present high concentrations of $\mu$-opioid receptors and demonstrate increases in regional blood flow after the exogenous administration of $\mu$-opioid recep- 


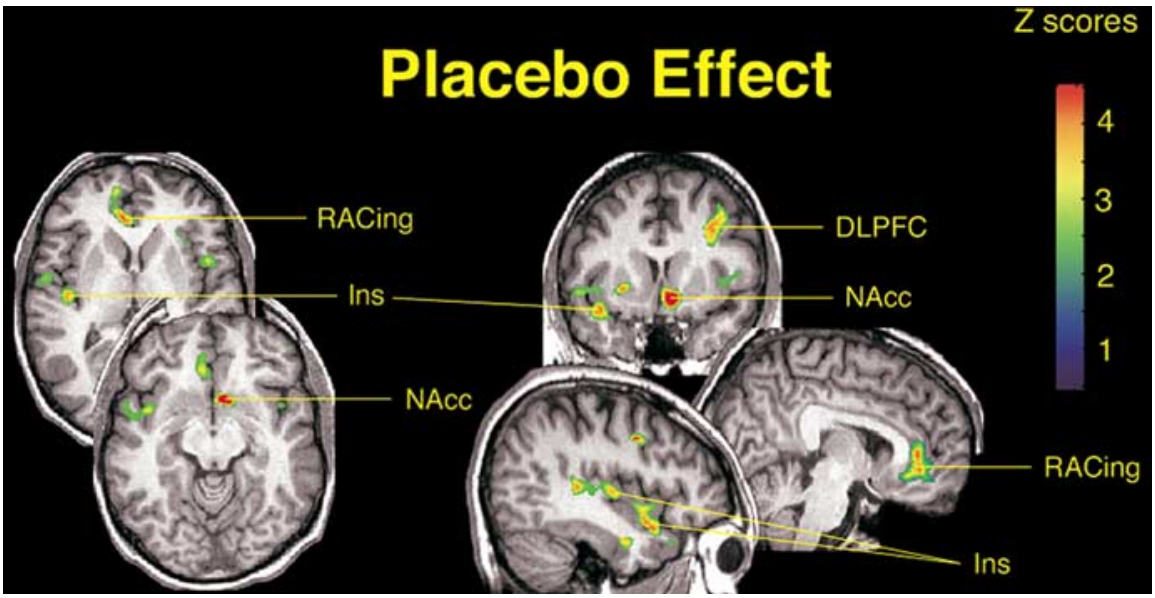

Figure 3. Effects of placebo on the activation of $\mu$-opioid receptor-mediated neurotransmission. After correction for multiple comparisons, significant effects of placebo on the activation of the $\mu$-opioid system $(n=14)$ were detected in the left DLPFC $(x$, $y$, z peak coordinates, $-36,13,39$; cluster size, $1403 \mathrm{~mm}^{3} ; z$ score, $\left.4.27 ; p<0.0001\right)$, rostral anterior cingulate (RACing; $x, y, z$, 14, 49, 13; cluster size, $3193 \mathrm{~mm}^{3}, z$ score, 4.18; $p<0.0001$ ), left nucleus accumbens (NAcc; $x, y, z,-7,11,-11$; cluster size, $1332 \mathrm{~mm}^{3} ; z$ score, 4.83; $p<0.0001$ ), and right anterior insula (Ins; $x, y, z, 41,10,-17$; cluster size, $844 \mathrm{~mm}^{3} ; z$ score, $4.15 ; p<$ $0.05)$. The posterior right insula achieved subthreshold levels of significance $\left(44,-15,4\right.$; cluster size, $732 \mathrm{~mm}^{3} ; z \mathrm{score}, 3.81 ; p<$ 0.0001 uncorrected for multiple comparisons). $z$ scores of statistical significance are represented by the pseudocolor scale on the right side of the image and are superimposed over an anatomically standardized MRI image in coronal views. The left side of the axial and coronal images corresponds to the right side of the body (contralateral to pain) (radiological convention).

neurotransmission, but it no longer reached statistical significance after correction for multiple comparisons (Fig. 3).

The psychophysical correlates associated with the placebo-induced activation of the endogenous opioid system were then examined. For these correlates, subjects were selected who showed a substantial placebo effect (i.e., $>10 \%$ change in the in vivo availability of $\mu$-opioid receptors after placebo administration). This threshold was selected as exceeding the typical interexperimental variability in PET $\mu$-opioid receptor measurements (Zubieta et al., 2005a). In the pregenual anterior cingulate, placebo-induced $\mu$-opioid system activation above those levels was significantly correlated with ratings of visual analog (VAS) pain intensity and pain unpleasantness, McGill Pain Questionnaire (MPQ) sensory subscale scores, and total MPQ scores. Placeboinduced activation of endogenous opioid neurotransmission in this region was also highly and positively correlated with a measure of pain tolerance.

tor agonists (Firestone et al., 1996; Adler et al., 1997; Schlaepfer et al., 1998; Casey et al., 2000; Wagner et al., 2001).

The endogenous opioid system, and specifically its activation of $\mu$-opioid receptors, thought to primarily mediate the observed effects of placebo and naloxone, as noted above, is additionally implicated in a number of other functions. These range from the regulation of central stress responses and pain, hypothalamicpituitary regulation of reproductive and stress hormones (e.g., ACTH and the immunologically active cortisol), and the adaptation and response to novel and emotionally salient stimuli (Watkins and Mayer, 1982; Akil et al., 1984; Kalin et al., 1988; Rubinstein et al., 1996; Sora et al., 1997; Nelson and Panksepp, 1998; Smith et al., 1998; Filliol et al., 2000; Drolet et al., 2001; Zubieta et al., 2001, 2003a; Moles et al., 2004). It therefore has the potential to affect not only placebo-induced analgesic effects but also a number of other physiological functions.

A recent study (Zubieta et al., 2005a) directly examined whether the introduction of a placebo with expectation of analgesia activates endogenous opioid neurotransmission, using PET and a $\mu$-opioid receptor-selective radiotracer. Under these conditions, activation of this neurotransmitter system is evidenced by reductions in the in vivo availability of synaptic $\mu$-opioid receptors to bind the radiolabeled tracer (Zubieta et al., 2001, 2002, 2003b; Bencherif et al., 2002).

The activation of the endogenous opioid system and $\mu$-opioid receptors was compared between sustained pain and sustained pain plus placebo conditions in a sample of 14 healthy males, aged 20-30 years. Significantly higher levels of activation were obtained for the condition in which placebo was administered. After correction for multiple comparisons, statistically significant effects of placebo on $\mu$-opioid system activation were obtained in the left (ipsilateral to pain) dorsolateral prefrontal cortex (DLPFC) [at Brodmann areas (BA) 8 and 9], pregenual rostral right (contralateral) anterior cingulate (BA 24 and 25), right (contralateral) anterior insular cortex, and left (ipsilateral) nucleus accumbens (Fig. 3). A second area within the contralateral insular cortex, in its posterior region, also showed changes in
In the right anterior insular cortex, significant correlations were obtained with the changes in VAS ratings of pain intensity and MPQ sensory and total MPQ scores. At the level of the left nucleus accumbens, significant correlations were obtained, in the same direction, with the change in VAS pain intensity ratings, MPQ affective subscale, and reductions in negative affect scores experienced during the challenge (Profile of Mood Scale). In the left dorsolateral prefrontal cortex, $\mu$-opioid system activation was negatively correlated with the expected analgesic effect as rated by the subjects before placebo administration.

The regions in which placebo administration increased the endogenous opioid neurotransmission primarily coincided with that observed by Wager et al. (2004) as reductions in paininduced metabolic demands as measured by fMRI during placebo administration (i.e., prefrontal cortex, pregenual anterior cingulate, and insular cortex). The regions implicated in the placebo analgesic effect were part of those in which prominent endogenous opioid neurotransmission and $\mu$-opioid receptor populations are present in humans (Gross-Isseroff et al., 1990; Gabilondo et al., 1995). The rostral anterior cingulate had also been noted to be more prominently activated in high placebo responders after $\mu$-opioid agonist administration (Petrovic et al., 2002).

This work takes the investigation of placebo effects directly into the realm of human brain neurotransmission, addressing the effects of cognitive expectations on neural chemical functions. The results presented are consistent with reports implicating the endogenous opioid system in the mediation of placebo analgesic effects, previously examined by their blockade after the systemic administration of naloxone (Gracely et al., 1983; Grevert et al., 1983; Levine and Gordon, 1984; Benedetti, 1996; Amanzio and Benedetti, 1999).

Examination of the individual data also highlighted that changes in neurochemical signaling induced by the introduction of a placebo did not represent an on-off phenomenon but rather a graded effect that was influenced, with relative independence, by a number of brain regions with complex "integrative-motiva- 


\section{Individual Data}

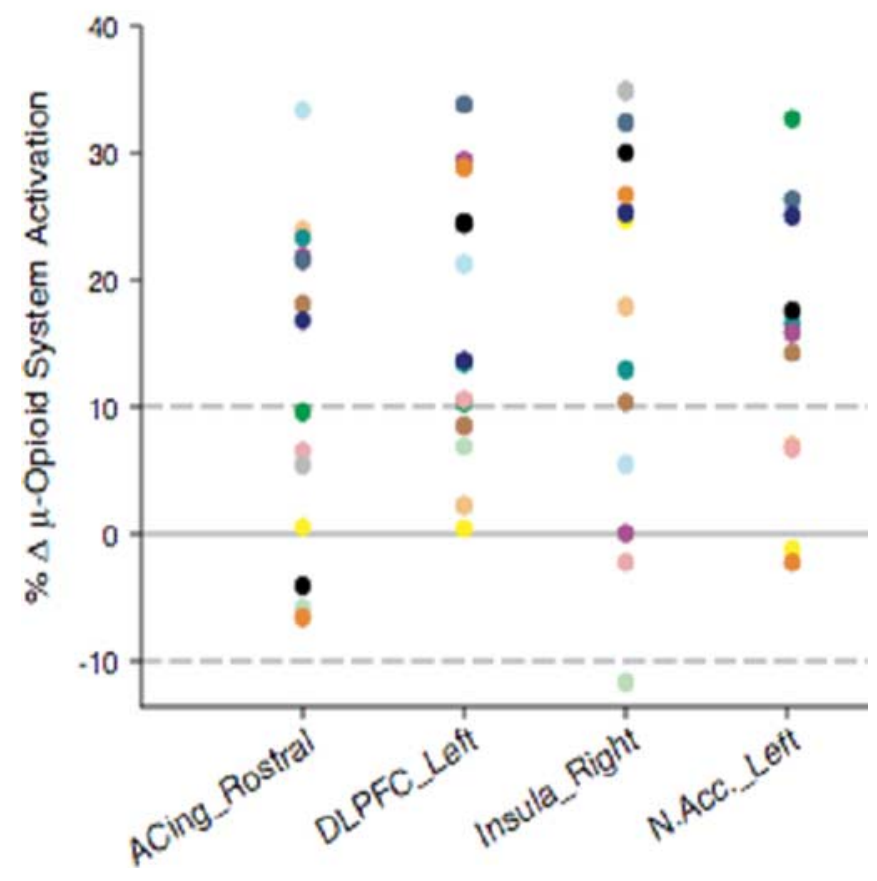

Figure 4. Individual data points for the magnitude of regional $\mu$-opioid system activation in response to the placebo intervention. Individual data points for the change in the binding potential measure ( $\mu$-opioid receptor availability in vivo; $B_{\max } / K_{\mathrm{d}}$ ) from the pain condition to the pain plus placebo condition. A threshold of $10 \%$ increase in the activation of this neurotransmitter system, evidenced as a reduction in the binding potential measure during the placebo condition, was used to identify individuals that responded with a robust placebo effect on the activation of this system in each of the regions (dotted line). Colors depict the data for each individual subject to highlight regional differences in the individual placebo response. ACing_Rostral, Rostral (pregenual) region of the anterior cingulate; DLPFC_Left, left dorsolateral prefrontal cortex; Insula_Right, right insular cortex; N.Acc._Left, left nucleus accumbens.

tional" functions. For example, some subjects presented with profound neurochemical responses to the placebo intervention in some but not other regions (Fig. 4). Multiple regression analyses were then conducted to examine whether individual differences in the pain experience (i.e., the analgesic placebo effect serves an adaptive function in the face of increased needs to reduce the individual experience of pain) could be driving some of the variations in the neurochemical response to the placebo. A multiple regression model that included sensory and affective qualities of pain, a measure of pain sensitivity, and the internal affective state of the volunteers during pain (in the absence of placebo) described $40-65 \%$ of the variance in the subsequent regional neurochemical responses to placebo. When the individual items in the model were examined, the internal affective state of the volunteers during pain (as measured with the Positive and Negative Affectivity Scale) and the affective quality of the pain (as measured with the MPQ pain affect subscale) were the only items reaching statistically significant correlations with regional endogenous opioid release after placebo administration. This was the case in the dorsolateral prefrontal cortex, pregenual anterior cingulate, anterior insular cortex, and nucleus accumbens (Zubieta et al., 2005b).

The studies and analyses presented above demonstrate that expectation of analgesia is an important factor in the engagement of objective, neurochemical antinociceptive responses to a pla- cebo and, furthermore, that these processes appear to involve the expectations of the perceived analgesic efficacy of the placebo, an effect that is mediated by endogenous opioid neurotransmission in the dorsolateral prefrontal cortex. However, a substantial proportion of the variance in the regional neurochemistry of placebo analgesia was explained by the experience of pain itself. In this regard, variations in pain sensitivity, in the affective qualities of the pain, as well as the internal affective state of the individual during pain explained a substantial proportion of the variance in the formation of the placebo analgesic effect. These findings seem to support the concept that placebo responses form part of adaptive mechanisms engaged as a function of the perceived needs of the organism, with modifiers, such as negative affective states, further regulating those responses. They also suggest that the study and understanding of individual variations in placebo responses is further complicated by the individual responses to the process (e.g., clinical pain) for which relief is expected.

These data are additionally consistent with the notion that placebo-responding regions and neurochemical systems (e.g., the endogenous opioid system and $\mu$-opioid receptors) are an intrinsic part of neuronal processes that mediate the interaction between positive environmental conditions (in the present case the suggestion of analgesia) and the corresponding physical and emotional responses of the individual. From a different perspective, disruptions in the function of these normal regulatory processes [e.g., dorsolateral prefrontal atrophy in chronic pain patients (Apkarian et al., 2004)] may explain the typically lower rates of placebo responding in the more persistent or severe forms of various illnesses. These may further represent points of vulnerability for the expression or maintenance of various pathological states.

\section{Functional neuroanatomy of placebo analgesia}

A recent fMRI study investigated the effects of expectations of placebo analgesia in a thermal pain model (Wager et al., 2004b). It used a single-trial design to separate activity induced by placebo treatment in anticipation of pain from subsequent changes in pain processing. In addition, the investigators defined painresponsive regions of interest in the group of participants and looked for evidence of decreased pain response in these regions with the placebo. Comparing results across two separate studies in different pain modalities provided convergent evidence for the reliability of findings. Evidence for prefrontal cortex increases during expectation of pain would suggest that placebo expectancies are active neurobiological processes that involve the frontal lobes. Evidence for decreases during pain would suggest that placebo treatment alters nociceptive sensory and/or affective processing, not just retrospective judgments about pain (Kienle and Kiene, 1997; Hrobjartsson and Gotzsche, 2001, 2004).

Placebo treatment decreased both reported pain and painevoked activity in the brain. There was a $22 \%$ reduction in reported pain $(p<0.001)$, with $>70 \%$ of participants showing placebo-induced reductions. Although placebo effects were significant in both experiments in this study, these particularly large effects were induced in experiment 2 using an expectancy manipulation procedure to enhance belief in the placebo (Price et al., 1999). Placebo also diminished the brain responses in a subset of pain-responsive regions, including the anterior insula and thalamus (contralateral to stimulation) and the anterior cingulate cortex. Furthermore, the greatest placebo effects in pain response were found late in stimulation. These late effects suggest that a substantial portion of the placebo response may reflect a modulation of limbic and paralimbic regions that are involved in the 


\section{Placebo-induced increases in fMRI}

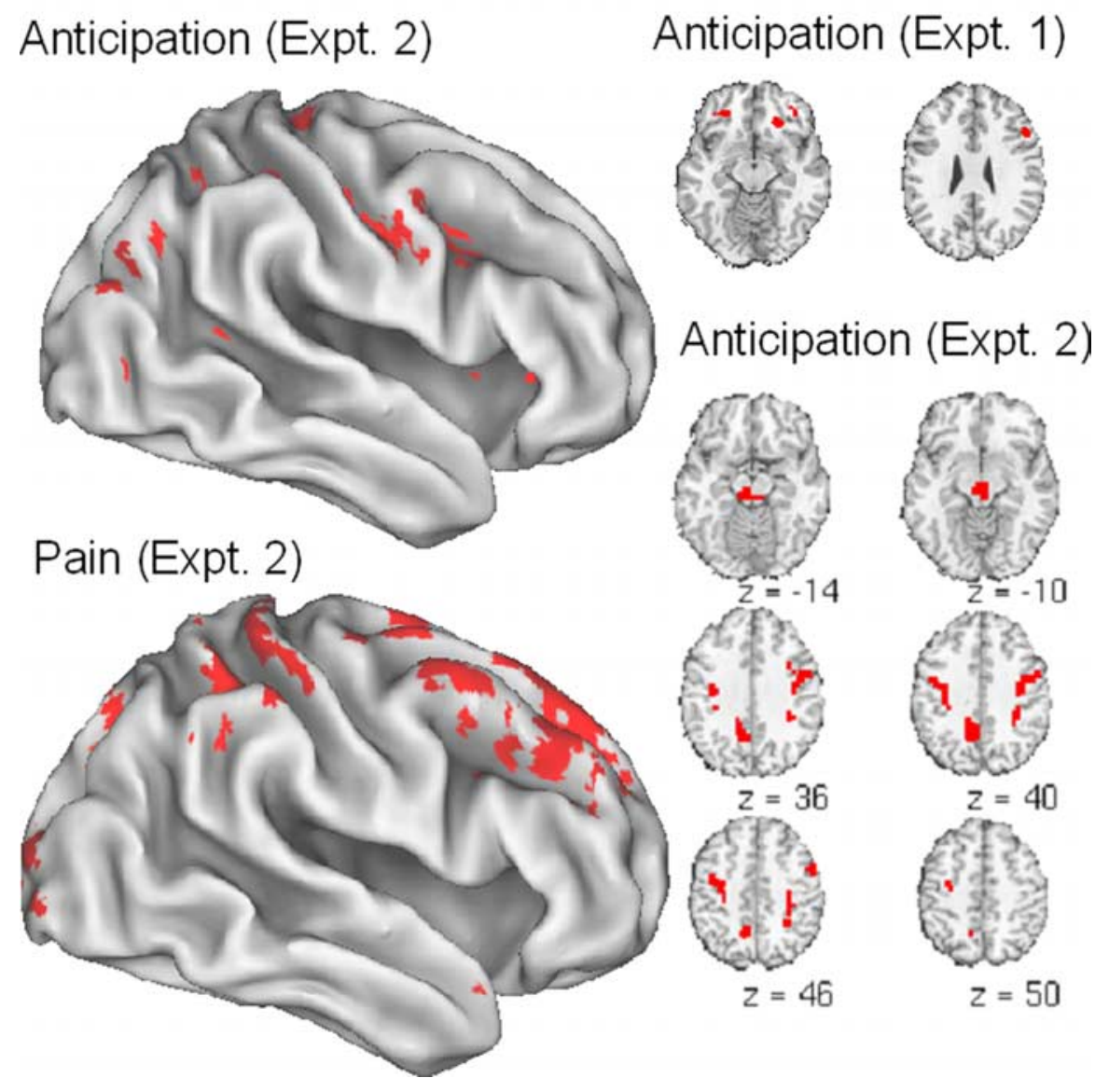

Figure 5. Placebo-induced increases (placebo-controlled) in anticipation of pain (top left and slices at right) and during pain experience (bottom left) (from Wager et al., 2004). The threshold for display is set at $p<0.005$, with the additional constraint of replication of effects within $10 \mathrm{~mm}$ across experiments 1 and 2 . For space reasons, selected activations are shown.

for experiment 2 shown in Fig. 5). These results indicated that placebo treatment engaged active prefrontal processing mechanisms, and their colocalization with activations from studies of working memory and cognitive control suggest that these regions may play a general role in representing expectancies and other elements of situational context across both cognitive and affective domains.

The gate control theory posits and much subsequent work on central regulation of pain has shown that the periaqueductal gray (PAG) exerts central control over spinal pain pathways (Melzack and Wall, 1965; Fields, 2004). The PAG receives projections from insula, anterior cingulate, nucleus accumbens, amygdala, and frontal cortex (Bragin et al., 1984; Ma and Han, 1991; Rizvi et al., 1992). Microstimulation of ventrolateral OFC in rats transiently attenuates nociceptive reflex responses, and this effect is blocked by lesion of the PAG (Zhang et al., 1997, 1998). Consistent with the notion that descending control is a mechanism of placebo analgesia, placebo treatment by Wager et al. (2004) induced activity in PAG during anticipation of pain. Surprisingly, the strongest increases were linked in time to the onset of the warning cue signaling upcoming pain. In addition, these increases were positively correlated with increases in OFC and DLPFC (Fig. 5), suggesting that opioid systems are engaged by positive expectations of analgesia.

However, this interpretation must be viewed cautiously. PAG neurons project

appraisal of pain. Activity in the anterior cingulate and, in particular, the anterior insula is associated with the subjective experience of pain (Craig et al., 2000) and other aversive emotional states (Wager et al., 2003; Singer et al., 2004; Wager and Feldman Barrett, 2004). Paradoxically, placebo-induced increases in activity were found in secondary somatosensory cortex. Clearly, future studies must disentangle the roles of each region of the "pain matrix" in pain processing, and interventions such as the ones described in this symposium can provide leverage points for characterizing the function of the system.

Because placebo-induced expectancies are formed and maintained in anticipation of pain, $\mathrm{AMRI}$ signal in the prefrontal cortex during pain anticipation might reflect the generation and maintenance of placebo-related expectancies. It was hypothesized that placebo treatment would induce increases in DLPFC (BA 9 and 46) and ventrolateral prefrontal cortex (VLPFC) (BA 45 and 47) because of their roles in generating and maintaining cognitive expectancies that guide memory retrieval and attention. Activity in these regions is also thought to play a key role in shaping perceptual processing in posterior brain regions (Posner, 1980; Allport, 1989; Desimone and Duncan, 1995; Handy et al., 2001). During the anticipation of pain, placebo increased activity in DLPFC, orbitofrontal cortex (OFC) (BA 11), and rostral dorsal anterior cingulate cortex (BA 24). Lateral and medial frontal increases with placebo continued through the pain period (results upwards to the telencephalon as well as downwards to the spinal cord, and it may well be that PAG modulates the central representation of pain through the activation of opioid release in cortical and limbic regions (Zubieta et al., 2005a). Another issue is the timing of PAG activity, which was found during expectation but not during pain. One explanation may be that both placebo and pain itself may increase PAG activity. During pain, placeboinduced increases in PAG may be offset by decreases attributable to reduced pain processing. This issue highlights the potential fruitfulness of separating brain measures of expectation and experience in disentangling the functions of interlocking feedback circuits in the brain.

As reviewed above, there is ample evidence that expectancybased placebo effects are mediated by endogenous opioids. Future studies may clarify the role of opioids in descending control versus modulation of affective elements of pain. The functions of descending and ascending opioid projections may be closely coupled; indeed, given the recurrent connectivity that is a hallmark of brain circuitry, it would be surprising if they were not. However, they may be functionally separable; the issue at stake is the level of the CNS at which nociceptive signals are modulated by placebo.

This review focuses on the effects of expectation, which may be directly linked to opioid activity that relieves pain. Positive expectations may also induce changes in several other systems that could impact pain: they could increase positive emotions and 
activate incentive motivational ("reward") systems, as suggested by the recent results of Zubieta et al. discussed above, or they could decrease anxiety. Little is known yet about the scope of psychological and neural systems that may be affected by placebo. However, the fMRI studies of Wager et al. (2004b) provide a hint that placebo treatment for pain may act by reducing anxiety: placebo-induced decreases in anticipatory responses were found in the amygdala and temporal poles, both of which have been associated with aversive expectancies (Phelps et al., 2001; Wager et al., 2003; Ochsner et al., 2004; Petrovic et al., 2005). Indeed, a recent study examining placebo-induced anxiolytic effects shares several key regions in common with Wager et al. (2004b), including rostral anterior cingulate cortex and OFC (Petrovic et al., 2005) (see Fig. 8). Changes in both anxiety and incentive motivational systems have widespread consequences for the organism, and more research is needed to understand the effects beliefs and expectations exert on brain function and the mechanisms by which they do so.

\section{Neural responses to placebo in clinical trials of antidepressants}

Major depression is another useful model to examine neurobiological mechanisms of the placebo effect, because placebo responses are common in antidepressant trials of many interventions, including medication, psychotherapy, and somatic treatments (DeRubeis et al., 1999, 2005; Kirsch and Sapirstein, 1998; Enserink, 1999; Khan et al., 2000; Quitkin and Klein, 2000; Quitkin et al., 2000; Walsh et al., 2002; Koerselman et al., 2004). As in clinical trials for other medical conditions, the effectiveness of a new antidepressant is determined by comparing an active treatment with a controlled comparison condition. Because there are a number of proven treatments for major depression, it has been suggested that placebo-controlled studies are no longer appropriate for testing potential new treatments. However, evidence of significant and increasing rates of placebo response in published antidepressant trials has justified their continued use (Khan et al., 2000; Andrews, 2001; Walsh et al., 2002). Complicating the picture of determining the efficacy of a new treatment in light of significant placebo effects is the additional confound of improvement in depressive symptoms attributable to the natural history of the disorder. Together, these synergistic effects have been interpreted by some as evidence that the active intervention actually contributes a relatively small percentage to the observed efficacy rates of published antidepressant drug trials (Kirsch and Sapirstein, 1998). Such observations of significant short-term placebo response rates are in contrast to continuation studies that demonstrate a significant advantage of maintenance medication over continued placebo treatment in preventing relapse and recurrence (Frank et al., 1990; Montgomery, 1996; Stewart et al., 1998, McGrath et al., 2000). These findings lay critical foundation for the design of experiments targeting placebo effect mechanisms, because the clinical data suggest that such effects are not sustained long term.

As outlined previously, the study of the placebo effect is the study of the psychosocial context specific to a particular trial situation that includes the expectation of clinical improvement and conditioning (Colloca and Benedetti, 2005; Finniss and Benedetti, 2005). Clinical practice works to maximize and reinforce the effects of expectation and conditioning but in the setting of a known effective treatment. Research trials, conversely, are focused on detecting significant clinical effects that can be unambiguously attributed to the active treatment under investigation and therefore work to reduce these phenomena. Thus, a standard
6-8 week double-blind, placebo-controlled clinical study would appear to provide a unique opportunity to examine synergistic mechanisms mediating depression remission, including those specific to the active treatment as well as those involved in expectation and conditioning, i.e., placebo effects. From this perspective, one might presume that the identification of pure placebomediated response changes would reveal a "final common pathway" for depression remission because the placebo group would be unaffected by nonspecific drug, cognitive, or lesion effects evoked by the medication, psychotherapy, or surgical procedure under investigation. As will be illustrated below, this presumption is likely incorrect, because mechanisms mediating different antidepressant treatments are themselves diverse. Instead, placebo effects seen with different treatments are more likely to track closely with the active treatment to which they are experimentally paired. To test such a hypothesis, studies of wellvalidated, efficacious treatments are needed to define these purported intervention-specific and response-specific effects.

Before examining neurobiological changes associated with placebo effects using either established or novel treatments, it is also important to consider the unavoidable confounds inherent in clinical studies of depressed patients. Given the current availability of a number of approved, effective treatments for depression, new trials of novel interventions rarely recruit treatmentnaive or first-episode patients and, as such, are potentially influenced by the knowledge (expectation) of the anticipated clinical endpoint (i.e., recovery or remission) as well as past conditioning and learning as to the usual time course of change in symptoms with similar treatments (i.e., other medications). Studies of first-episode, never-before-treated patients provides the most theoretically ideal design to study these conditioning and expectation effects because these patients have no experience with either clinical recovery or the trajectory of symptom improvement. Unlike single-dose trials of an intervention such as the intravenous analgesia or intraoperative DBS studies described previously, it is generally considered unethical to include a negative expectation control condition during a multi-week depression trial. Furthermore, antidepressants do not work acutely, requiring on average a minimum of 3 weeks to see clinical effects. The mandates of informed consent actually require disclosure of the possible time course of likely change in target symptoms as well as the nature and scope of all potential side effects (Barsky et al., 2002), further prohibiting such a control group. The role of personality and dispositional factors such as optimism (or the antithesis) are now also being reconsidered as important contributors (Geers et al., 2005). Taking these various factors into account, repeated poor response to previous treatments might actually be predicted to result in lower placebo response to a novel intervention because of negative expectation and conditioning (Gunstad and Suhr, 2001). This hypothesis, however, would appear to be contradicted by findings of consistently low placebo rates with somatic treatments such as electroconconvulsive therapy (ECT), although the typical patient has generally already failed multiple previous interventions (Pagnin et al., 2004). Such observations, nonetheless, suggest a more complex interaction between mechanisms mediating expectation and conditioning effects for a given antidepressant treatment and the heterogeneity of the depressed patient population under study. These factors necessitate caution in both the design and interpretation of studies examining explicit placebo effects in what is often a heterogeneous group of depressed subjects.

With these variables in mind, PET measures of regional glucose metabolism [using the fluorodeoxyglucose (FDG) method] 


\section{Treatment-specific FDG PET Change Patterns}

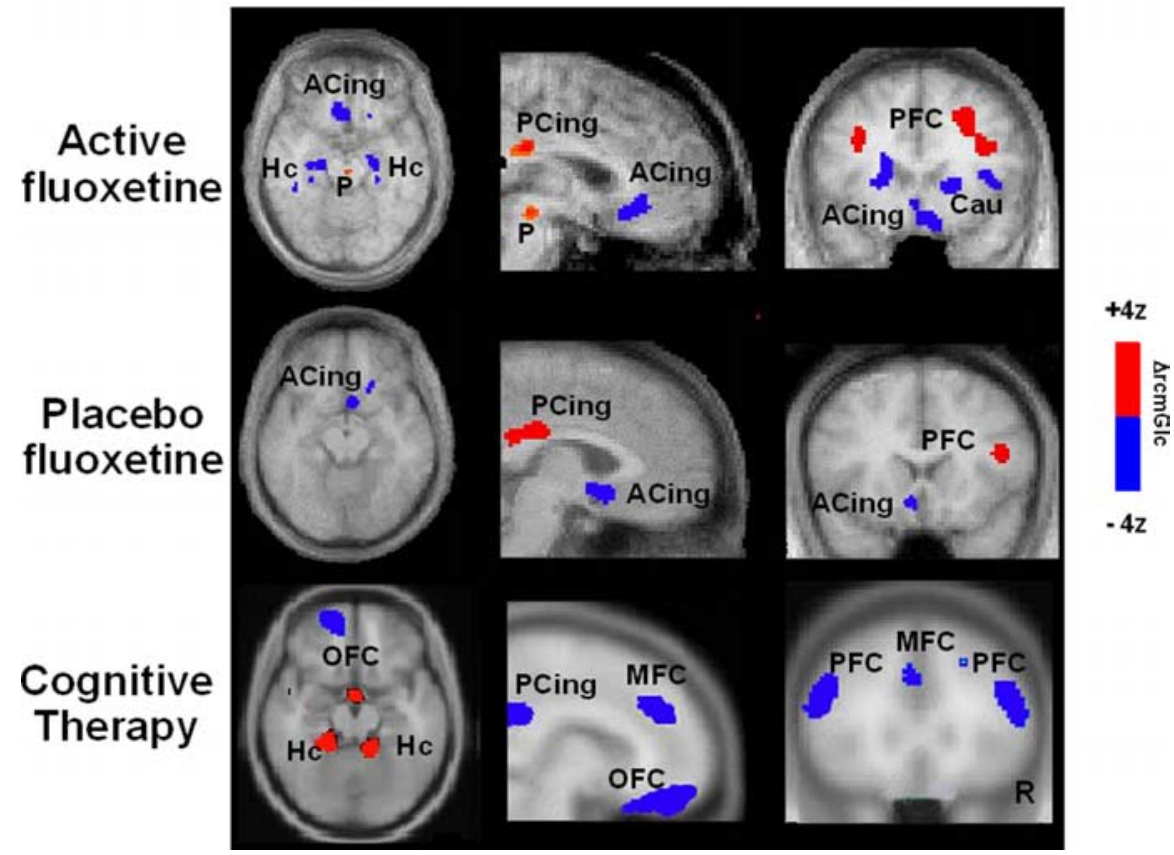

Figure 6. Changes in regional glucose metabolism (FDG PET) in fluoxetine (top), placebo (middle), and cognitive (bottom) therapy responders measured before and after a standard course of each respective treatment. Axial (left), sagittal (middle), and coronal (right) views; increases are in red, and decreases are in blue. The fluoxetine and placebo group were studied as part of the same double-blind controlled experiment. A common pattern of cortical increases and limbic-paralimbic decreases is seen in both groups, with the active fluoxetine group showing additional changes in the brainstem, hippocampus, insula, and caudate. In contrast, CBT response is associated with a distinctly different pattern: dorsolateral and medial frontal decreases and hippocampal increases. These findings suggest that the placebo changes are unlikely attributable to passive psychotherapy effects but rather specific effects attributable to the effects of expectation and conditioning facilitated by the psychosocial context of the trial. Slice location is in millimeters relative to anterior commissure. Numbers are Brodmann designations. ACing, Subgenual cingulate BA 25; PCing, posterior cingulate; $\mathrm{P}$, pons; $\mathrm{Hc}$, hippocampus; PFC, prefrontal cortex BA 9; Ins, anterior insula; Cau, caudate; OFC, orbital frontal cortex BA 11; MFC, medial frontal cortex BA 9.

and regional $\mathrm{CBF}$ have proven to be sensitive indices of brain function in both the untreated depressed state and after various treatments. Changes in cortical (prefrontal and parietal), limbicparalimbic (cingulate, amygdala, and insula), and subcortical (caudate/pallidum, thalamus, and brainstem) regions have been described after such diverse treatments as medication, psychotherapy, sleep deprivation, ECT, repetitive transcranial magnetic stimulation ablative surgery, and DBS (for review, see Mayberg, 2003). Although normalization of frontal abnormalities is the best-replicated finding, other regional effects are commonly reported with variable patterns with different treatments. These modality-specific effects are consistent with the hypothesis that different interventions modulate specific regional targets, resulting in a variety of complementary, adaptive chemical and molecular changes sufficient to reestablish a euthymic, remitted state (Hyman and Nestler, 1996; Vaidya and Duman, 2001). The functional neural architecture of these observed change patterns provides a foundation to examine putative brain mechanisms mediating placebo effects under comparable treatment conditions. If expectation and conditioning are the principle mediators of such effects (Colloca and Benedetti, 2005; Finniss and Benedetti, 2005), one would predict comparable patterns between active and sham-treated responders in a given experiment, if pathways mediating expectation and conditioned learning are not otherwise impaired (for review, see Schultz, 2002).

To first test this hypothesis, cerebral glucose metabolism was measured using FDG PET in a group of depressed men partici- pating in an inpatient, randomized, placebo-controlled study of the approved antidepressant fluoxetine (Mayberg et al., 2000, 2002). Scans were acquired at three time points: before treatment (baseline) and again after 1 and 6 weeks of treatment. Brain changes associated with clinical response (6 weeks of treatment relative to baseline) were first assessed separately for the active drug and placebo groups; change patterns were then compared. Anatomically concordant metabolic changes were seen with both active fluoxetine and placebo response: increases in prefrontal (at BA 9/46), parietal (BA 40), and posterior cingulate (BA31), and decreases in subgenual cingulate (BA 25) (Fig. 6, rows $1,2)$. The magnitude of regional fluoxetine changes was generally greater than placebo. Unique to fluoxetine were additional increases in pons and decreases in caudate, insula, and hippocampus, regions with known efferent connections to both subgenual cingulate and prefrontal cortex, in which changes were seen in both groups. There were no regional changes unique to placebo at 6 weeks. Unfortunately, there were inadequate numbers of placebo nonresponders completing the 6 week trial to evaluate placebo nonresponse patterns.

Although not tested by an extended continuation study, it was speculated from these findings that the hippocampal, brainstem, striatal, and insula changes seen uniquely in drug-treated responders might be important to clinical response long term. In support of this argument, failed response to active fluoxetine was associated with persistent hippocampal increases and posterior cingulate decreases, the pattern seen in all active drug-treated subjects after 1 week of treatment, regardless of eventual outcome (Mayberg et al., 2000). The reversal of the week 1 pattern at 6 weeks in responders suggested a process of neural adaptation in specific brain regions over time with chronic treatment. The presence of an inverse pattern in responders and nonresponders further suggests that failure to induce these adaptive changes may underlie treatment nonresponse. These respondernonresponder differences are also consistent with the time course and location of changes identified in animal studies of selective serotonin reuptake inhibitors antidepressants that emphasize early brainstem and hippocampal changes and late cortical effects (Duman et al., 1999; Freo et al., 2000; Blier, 2001; Vaidya and Duman, 2001).

Without a comparable study contrasting sham treatment to a different active treatment modality such as cognitive or psychotherapy, one could easily conclude from this study that the subgenual cingulate and prefrontal changes shared by both active and sham medication reflect a final common pathway for depression remission. At the time these data were first analyzed, there were not yet published studies demonstrating consistent psychotherapy-specific or cognitive therapy-specific patterns (with or without a sham condition) to negate such a conclusion. Another problem was that the 6 week scan findings provided no real clues as to which regions were most likely linked to either 
expectation or conditioning, the putative mechanisms of placebo effects. Two subsequent studies addressed these open issues.

First, the issue of nonspecific but known therapeutic effects of the inpatient environment were considered. If the common subgenual and prefrontal changes seen in the fluoxetine-placebo study were in fact attributable to nonspecific psychological effects, one would expect similar and likely more robust changes with a more formal course of a specific psychological intervention. Contrary to this hypothesis, recent studies of clinical response to either cognitive behavioral therapy (CBT) (Goldapple et al., 2004) or interpersonal psychotherapy (IPT) (Brody et al., 2001; Martin et al., 2001) demonstrate very different regional brain change patterns from those seen with placebo (Mayberg et al., 2002). Both CBT and IPT are associated with prominent prefrontal decreases with other regional effects specific to each psychotherapy strategy. With clinical response to cognitive behavioral therapy, additional changes were seen in regions not targeted by medication, including the orbital frontal and medial frontal cortex and dorsal anterior cingulate (Fig. 6, bottom).

The change patterns seen with these specific psychotherapies provide preliminary evidence refuting the hypothesis that placebo response is mediated by changes in a common antidepressant response pathway. These findings additionally suggest that placebo response is also not the result of uncontrolled, nonspecific psychological treatment effects. Brain changes with placebo response, in fact, most closely match the active drug-response pattern to which it was experimentally yoked (conditioned), similar to that seen in acute placebo-controlled experiments discussed elsewhere in this review (i.e., striatal dopamine changes with both dopamine agonist and sham medication for Parkinson's disease; cingulate and brainstem blood flow changes with acute opiate and placebo opiate analgesia) (de la FuenteFernandez et al., 2001; Petrovic et al., 2002). Obviously, a placebo-controlled CBT trial will be necessary to fully definitely test the hypothesis that placebo-response changes mirror the specific intervention to which they are paired, meaning that placebo-CBT would be anticipated to overlap true CBT changes, not those seen with placebo medication. A wait-list control group will also be needed to address effects potentially attributable to spontaneous remission with either treatment.

Last, and not yet addressed by the previous analyses, is the specific contribution of expectation. Although the 6 week placebo-controlled fluoxetine study was not designed to examine such effects explicitly, the availability of a scan early in the course of treatment before clinical response combined with the known and expected delay in clinical symptom changes with this class of medication has allowed for some exploratory analyses. Pertinent to interpreting the results is converging evidence from animal models and human imaging studies implicating the ventral striatum and orbital frontal cortex in the expectation and delivery of reward during various conditioned learning paradigms (Ikemoto and Panksepp, 1999; Schultz et al., 2000; Schultz, 2002; Knutson and Cooper, 2005, among many). Although beyond the scope of this symposium, studies further demonstrate that dopaminemediated striatal activity, when paired with specific sensory stimuli, can enhance corticocortical connections and facilitate neural plasticity, in keeping with the behavioral salience of the stimuli (Bao et al., 2001).

Extrapolating liberally from these many preclinical experiments, metabolic changes occurring at 1 week of fluoxetine (or sham) treatment relative to baseline were assessed as a function of eventual 6 week response outcome, during what one might consider a period of ongoing expectation for clinical benefit (i.e., delivery of reward). Because none of the patients showed any signs of clinical improvement at this 1 week time point, differences between eventual drug responders, placebo responders, and drug nonresponders were interpreted as an index of the expectation component of the later antidepressant response. It was postulated that such reward expectation effects would be most robust in those patients who went on to do well compared with those patients that failed to improve (i.e., successful conditioned expectation). It was further speculated that this "expectation" pattern would involve different regions than those defining the time course of active medication effects (hippocampal and brainstem increases, posterior cingulate decreases). As illustrated in Figure 7 , there were in fact unique ventral striatal and orbital frontal changes in both placebo and drug responders at 1 week of treatment. Such changes were not seen in the eventual drug nonresponders. Furthermore, this change pattern was not seen at 6 weeks when the antidepressant response was well established, consistent with differential patterns of activity with expectation and delivery of reward in animal models (Schultz et al., 2000; Knutson and Cooper, 2005). Additional multivariate analyses, examining the interaction of these ventral striatal changes with the rest of the brain over time, further identified an ongoing correlation between ventral striatal activity and lateral prefrontal 


\section{Increased activity in self-regulation tasks}

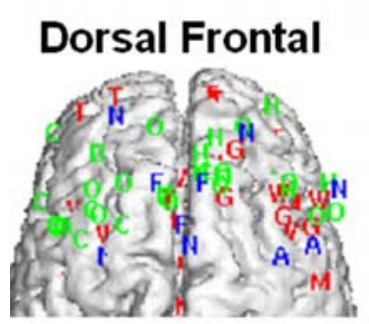
Orbitofrontal

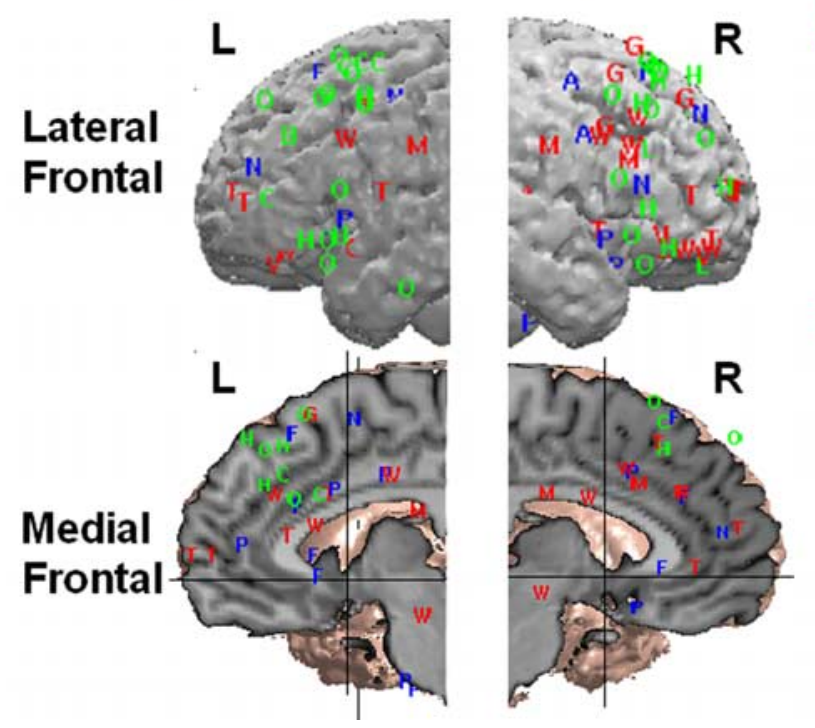

Opioid increases

F Firestone 1996

A Adler 1997

N Wagner 2001

P Petrovic 2002

Emotion regulation

L Levesque 2003

C Ochsner 2002

O Ochsner 2004

H Phan 2004

B Bishop 2004

\section{Placebo}

W Wager 2004, antic. G Wager 2004, pain I Lieberman 2004

V Petrovic 2002

T Petrovic 2005

M Mayberg 2002

Figure 8. Regions of the frontal lobes showing increased activity in recent studies of self-regulation. Increases are shown for delivery of opiate analgesics compared with resting nondrug control states (blue letters), downregulation of aversive emotional experience (green) through emotional reappraisal, and placebo effects on pain or emotional processing (red). Some peaks reflect regions for which increases in activity are correlated with reductions in negative emotional experience or pain. One exception is the study by Bishop et al. (2004) (B), in which frontal activation was correlated with reduced state anxiety. Peak locations from the same study within $12 \mathrm{~mm}$ were averaged together for clarity of presentation.

and subgenual cingulate changes at both the early and late time points, which was predictive of clinical outcome with both active drug and placebo (data not shown). Such functional connectivity analyses are consistent with preclinical models of striatalmediated cortical plasticity, although the role of dopamine in the depression study is unknown (Bao et al., 2001). Although future studies will require more explicit evaluations of patients' expectations during a specific clinical trial, these retrospective analyses demonstrate proof-of-principle that such studies can provide important clues as to the mechanisms mediating placebo effects in trials of diverse antidepressant treatments.

\section{Relationship of placebo effects to other} self-regulatory processes

A view of the results presented, particularly those in the field of pain and in the context of other recent studies on self-regulation, is that the areas engaged by placebo may be part of a general circuit underlying the voluntary regulation of affective responses. Figure 8 shows data from 15 recent studies of placebo, regulation of emotions, and activation by actual opiate drugs. The superposition of peak coordinates of increased activation in each of these conditions reveals a set of frontal regions that appear to be consistently increased during diverse tasks in which negative affect must be suppressed. On the lateral surface, these regions include the DLPFC, VLPFC, and possibly a third cluster of activations around the rostral PFC. On the medial surface, two clusters ap- pear around the midrostral dorsal anterior cingulate and neighboring superior medial PFC. On the orbital surface, many peaks are grouped around the medial orbital sulcus bilaterally.

Each of these regions, except those in the OFC and right VLPFC, have been shown to increase activation with delivery of an opiate analgesic (Firestone et al., 1996; Adler et al., 1997; Wagner et al., 2001; Petrovic et al., 2002). Both dorsal and ventral PFC have also been consistently activated in the voluntary positive reinterpretation of the meaning of aversive visual stimuli (Ochsner et al., 2002, 2004; Levesque et al., 2003; Phan et al., 2005) and correlated with reduced amygdala activation (Lieberman et al., 2005) and anxiety (Bishop et al., 2004). In a study of placebo regulation of affective responses to pictures, Petrovic et al. (2005) found placeboinduced activity in both DLPFC and VLPFC and the midrostral cingulate. Both increases in these areas and placeboinduced decreases in amygdala correlated with larger placebo effects in reported emotion. Rainville et al. (1997) found that the same region of cingulate was modulated by hypnosis in a pain context. Although these different varieties of selfregulation have not been tested in the same study, the colocalization of results suggests that there may be a general system for selfregulation that applies to both emotions and pain and to both voluntary strategies and the externally generated appraisals that produce placebo effects as well.

At the psychological level, much work remains to be done to disentangle the psychological mechanisms that may be driving these common activations and placebo effects. One hypothesis is that placebo effects are driven by executive attention: appraisals of safety may lead to increased use of self-distraction strategies. Dorsal and ventral PFC are activated by a large class of cognitively demanding conditions. Numerous studies of distraction from pain (for review, see Petrovic and Ingvar, 2002) also produce activation in these regions. Meta-analyses of working memory and executive attention have also revealed similar activation patterns (Wager and Smith, 2003; Wager et al., 2004a).

Another hypothesis is that placebo effects reduce anxiety, which in turn reduces pain (Vase et al., 2003). This explanation does not seem sufficient to account for the widespread activation in frontal systems found across studies. However, the finding of placebo-induced amygdala decreases suggests that the threat value of pain-predicting cues is decreased with placebo. A third alternative is that this network is subserving the process of meaning generation and appraisal of current and predicted events (Lazarus, 1991). Effective placebo treatment may engender and active reevaluation of the significance of pain, which engages $\mathrm{OFC}$ and lateral prefrontal systems in the generation and maintenance of short-term context that biases ongoing nociceptive and affective processing (Miller and Cohen, 2001). Clearly, a complete psychological explanation of placebo effects remains to be elucidated. However, as evidence from the neural and psycho- 
logical levels is gathered and integrated, we are gaining a surer and more complete understanding of the human self-regulatory faculties with which evolution has equipped us for effective social, emotional, and physical health.

\section{References}

Ader R (2003) Conditioned immunomodulation: research needs and directions. Brain Behav Immun 17:S51-S57.

Adler LJ, Gyulai FE, Diehl DJ, Mintun MA, Winter PM, Firestone LL (1997) Regional brain activity changes associated with fentanyl analgesia elucidated by positron emission tomography. Anesth Analg 84:120-126.

Akil H, Watson S, Young E, Lewis M, Khachaturian H, Walker J (1984) Endogenous opioids: biology and function. Annu Rev Neurosci 7:223-255.

Allport A (1989) Visual attention. In: Foundations of cognitive science (Posner MI, ed). Cambridge, MA: MIT.

Amanzio M, Benedetti F (1999) Neuropharmacological dissection of placebo analgesia: expectation-activated opioid systems versus conditioning-activated specific subsystems. J Neurosci 19:484-494.

Andrews G (2001) Placebo response in depression: bane of research, boon to therapy. Br J Psychiatry 178:192-194.

Apkarian AV, Sosa Y, Sonty S, Levy RM, Harden RN, Parrish TB, Gitelman DR (2004) Chronic back pain is associated with decreased prefrontal and thalamic gray matter density. J Neurosci 24:10410-10415.

Bao S, Chan VT, Merzenich MM (2001) Cortical remodeling induced by activity of ventral tegmental dopamine neurons. Nature 412:79-83.

Barsky AJ, Saintfort R, Rogers MP, Borus JF (2002) Nonspecific medication side effects and the nocebo phenomenon. JAMA 287:622-627.

Bencherif B, Fuchs PN, Sheth R, Dannals RF, Campbell JN, Frost JJ (2002) Pain activation of human supraspinal opioid pathways as demonstrated by $\left[{ }^{11} \mathrm{C}\right]$-carfentanil and positron emission tomography (PET). Pain 99:589-598.

Benedetti F (1996) The opposite effects of the opiate antagonist naloxone and the cholecystokinin antagonist proglumide on placebo analgesia. Pain 64:535-543.

Benedetti F (1997) Cholecystokinin type-A and type-B receptors and their modulation of opioid analgesia. News Physiol Sci 12:263-268.

Benedetti F, Amanzio M, Maggi G (1995) Potentiation of placebo analgesia by proglumide. Lancet 346:1231.

Benedetti F, Amanzio M, Baldi S, Casadio C, Maggi G (1999a) Inducing placebo respiratory depressant responses in humans via opioid receptors. Eur J Neurosci 11:625-631.

Benedetti F, Arduino C, Amanzio M (1999b) Somatotopic activation of opioid systems by target-directed expectations of analgesia. J Neurosci 19:3639-3648.

Benedetti F, Pollo A, Lopiano L, Lanotte M, Vighetti S, Rainero I (2003) Conscious expectation and unconscious conditioning in analgesic, motor and hormonal placebo/nocebo responses. J Neurosci 23:4315-4323.

Benedetti F, Colloca L, Torre E, Lanotte M, Melcarne A, Pesare M, Bergamasco B, Lopiano L (2004) Placebo-responsive Parkinson patients show decreased activity in single neurons of subthalamic nucleus. Nat Neurosci 7:587-588.

Bishop S, Duncan J, Brett M, Lawrence AD (2004) Prefrontal cortical function and anxiety: controlling attention to threat-related stimuli. Nat Neurosci 7:184-188.

Blier P (2001) Crosstalk between the norepinephrine and serotonin systems and its role in the antidepressant response. J Psychiatry Neurosci [Suppl] 26:S3-S10.

Bragin EO, Yeliseeva ZV, Vasilenko GF, Meizerov EE, Chuvin BT, Durinyan RA (1984) Cortical projections to the periaqueductal grey in the cat: a retrograde horseradish peroxidase study. Neurosci Lett 51:271-275.

Brody AL, Saxena S, Stoessel P, Gillies LA, Fairbanks LA, Alborzian S (2001) Regional brain metabolic changes in patients with major depression treated with either paroxetine or interpersonal therapy. Arch Gen Psychiatry 58:631-640.

Casey K, Svensson P, Morrow T, Raz J, Jone C, Minoshima S (2000) Selective opiate modulation of nociceptive processing in the human brain. J Neurophysiol 84:525-533.

Colloca L, Benedetti F (2005) Placebos and painkillers: is mind as real as matter? Nat Rev Neurosci 6:545-552.

Colloca L, Lopiano L, Lanotte M, Benedetti F (2004) Overt versus covert treatment for pain, anxiety and Parkinson's disease. Lancet Neurol 3:679-684.

Craig AD, Chen K, Bandy D, Reiman EM (2000) Thermosensory activation of insular cortex. Nat Neurosci 3:184-190.

de la Fuente-Fernandez R, Ruth TJ, Sossi V, Schulzer M, Calne DB, Stoessl AJ (2001) Expectation and dopamine release: mechanism of the placebo effect in Parkinson's disease. Science 293:1164-1166.

DeRubeis RJ, Gelfand LA, Tang TZ, Simons AD (1999) Medications versus cognitive behavior therapy for severely depressed outpatients: megaanalysis of four randomized comparisons. Am J Psychiatry 156:1007-1013.

DeRubeis RJ, Hollon SD, Amsterdam JD, Shelton RC (2005) Cognitive therapy vs medications in the treatment of moderate to severe depression. Arch Gen Psychiatry 62:409-416.

Desimone R, Duncan J (1995) Neural mechanisms of selective visual attention. Annu Rev Neurosci 18:193-222.

Drolet G, Dumont EC, Gosselin I, Kinkead R, Laforest S, Trottier JF (2001) Role of endogenous opioid system in the regulation of the stress response. Prog Neuropsychopharmacol Biol Psychiatry 25:729-741.

Duman RS, Malberg J, Thome J (1999) Neural plasticity to stress and antidepressant treatment. Biol Psychiatry 19:1181-1191.

Enserink M (1999) Can the placebo be the cure? Science 284:238-240.

Fields H (2004) State-dependent opioid control of pain. Nat Rev Neurosci 5:565-575.

Filliol D, Ghozland S, Chluba J, Martin M, Matthes H, Simonin F, Befort K, Gaveriaux-Ruff C, Dierich A, Le MM, Valverde O, Maldonado R, Kieffer B (2000) Mice deficient for delta- and mu-opioid receptors exhibit opposing alterations of emotional responses. Nat Genet 25:195-200.

Finniss DG, Benedetti F (2005) Mechanisms of the placebo response and their impact on clinical trails and clinical practice. Pain 114:3-6.

Firestone L, Gyulai F, Mintun M, Adler L, Urso K, Winter P (1996) Human brain activity response to fentanyl imaged by positron emission tomography. Anesth Analg 82:1247-1251.

Frank E, Kupfer DJ, Perel JM, Cornes C, Jarrett DB, Mallinger AG, Thase ME, McEachran AB, Grochocinski VJ (1990) Three-year outcomes for maintenance therapies in recurrent depression. Arch Gen Psychiatry 47:1093-1099.

Freo U, Ori C, Dam M, Merico A, Pizzolato G (2000) Effects of acute and chronic treatment with fluoxetine on regional glucose cerebral metabolism in rats: implications for clinical therapies. Brain Res 854:35-41.

Gabilondo A, Meana J, Garcia-Sevilla J (1995) Increased density of muopioid receptors in the postmortem brain of suicide victims. Brain Res 682:245-250.

Geers AL, Helfer SG, Kosbab K, Weiland PE, Landry SJ (2005) Reconsidering the role of personality in placebo effects: dispositional optimism, situational expectations, and the placebo response. J Psychosom Res $58: 121-127$.

Goebel MU, Trebst AE, Steiner J, Xie YF, Exton MS, Frede S, Canbay AE, Michel MC, Heemann U, Schedlowski M (2002) Behavioral conditioning of immunosuppression is possible in humans. FASEB J 16:1869-1873.

Goldapple K, Segal Z, Garson C, Lau M, Bieling P, Kennedy S, Mayberg H (2004) Modulation of cortical-limbic pathways in major depression: treatment specific effects of cognitive behavior therapy compared to paroxetine. Arch Gen Psychiatry 61:34-41.

Gracely RH, Dubner R, Wolskee PJ, Deeter WR (1983) Placebo and naloxone can alter post-surgical pain by separate mechanisms. Nature 306:264-265.

Grevert P, Albert L, Goldstein A (1983) Partial antagonism of placebo analgesia by naloxone. Pain 16:129-143.

Gross-Isseroff R, Dillon K, Israeli M, Biegon A (1990) Regionally selective increases in mu opioid receptor density in the brains of suicide victims. Brain Res 530:312-316.

Gunstad J, Suhr JA (2001) "Expectation as etiology" versus "the good old days": postconcussion syndrome symptom reporting in athletes, headache sufferers, and depressed individuals. J Int Neuropsychol Soc 7:323-333.

Handy TC, Green V, Klein RM, Mangun GR (2001) Combined expectancies: event-related potentials reveal the early benefits of spatial attention that are obscured by reaction time measures. J Exp Psychol Hum Percept Perform 27:303-317.

Hrobjartsson A, Gotzsche PC (2001) Is the placebo powerless? An analysis 
of clinical trials comparing placebo with no treatment. N Engl J Med 344:1594-1602.

Hrobjartsson A, Gotzsche PC (2004) Is the placebo powerless? Update of a systematic review with 52 new randomized trials comparing placebo with no treatment. J Intern Med 256:91-100.

Hyman SE, Nestler EJ (1996) Initiation and adaptation: a paradigm for understanding psychotropic drug action. Am J Psychiatry 153:151-162.

Ikemoto S, Panksepp J (1999) The role of nucleus accumbens dopamine in motivated behavior: a unifying interpretation with special reference to reward-seeking. Brain Res Rev 31:6-41.

Kalin N, Shelton S, Barksdale C (1988) Opiate modulation of separationinduced distress in non-human primates. Brain Res 440:285-292.

Khan A, Warner HA, Brown WA (2000) Symptom reduction and suicide risk in patients treated with placebo in antidepressant clinical trials: an analysis of the FDA database. Arch Gen Psychiatry 57:311-317.

Kienle GS, Kiene H (1997) The powerful placebo effect: fact or fiction? J Clin Epidemiol 50:1311-1318.

Kirsch I, Sapirstein G (1998) Listening to Prozac but hearing placebo: a meta-analysis of antidepressant medication. Prevention and treatment, Vol I, article 0002a, available at http://journals.apa.org/prevention/ volume1/pre0010002a.html.

Knutson B, Cooper JC (2005) Functional magnetic resonance imaging of reward prediction. Curr Opin Neurol 18:411-417.

Koerselman F, Laman DM, van Duijn H, van Duijn MA, Willems MA (2004) A 3-month, follow-up, randomized, placebo-controlled study of repetitive transcranial magnetic stimulation in depression. J Clin Psychiatry 65:1323-1328.

Lazarus RS (1991) Cognition and motivation in emotion. Am Psychol 46:352-367.

Levesque J, Eugene F, Joanette Y, Paquette V, Mensour B, Beaudoin G, Leroux JM, Bourgouin P, Beauregard M (2003) Neural circuitry underlying voluntary suppression of sadness. Biol Psychiatry 53:502-510.

Levine JD, Gordon NC (1984) Influence of the method of drug administration on analgesic response. Nature 312:755-756.

Levine JD, Gordon NC, Fields HL (1978) The mechanisms of placebo analgesia. Lancet 2:654-657.

Lieberman MD, Jarcho JM, Berman S, Naliboff BD, Suyenobu BY, Mandelkern M, Mayer EA (2004) The neural correlates of placebo effects: a disruption account. NeuroImage 22:447-455.

Lieberman MD, Hariri A, Jarcho JM, Eisenberger NI, Bookheimer SY (2005) An fMRI investigation of race-related amygdala activity in AfricanAmerican and Caucasian-American individuals. Nat Neurosci 8:720-722.

Lipman JJ, Miller BE, Mays KS, Miller MN North WC, Byrne WL (1990) Peak B endorphin concentration in cerebrospinal fluid: reduced in chronic pain patients and increased during the placebo response. Psychopharmacology 102:112-116.

Ma QP, Han JS (1991) Neurochemical studies on the mesolimbic circuitry of antinociception. Brain Res 566:95-102.

Martin SD, Martin E, Rai SS, Richardson MA, Royall R (2001) Brain blood flow changes in depressed patients treated with interpersonal psychotherapy or venlafaxine hydrochloride. Arch Gen Psychiatry 58:641-664.

Mayberg HS (2003) Modulating dysfunctional limbic-cortical circuits in depression: towards development of brain-based algorithms for diagnosis and optimised treatment. Br Med Bull 65:193-207.

Mayberg HS, Brannan SK, Mahurin RK, McGinnin S, Silva JA, Tekell JL, Jerabek PA, Martin CC, Fox PT (2000) Regional metabolic effects of fluoxetine in major depression: serial changes and relationship to clinical response. Biol Psychiatry 48:830-843.

Mayberg HS, Silva JA, Brannan SK, Tekell JL, McGinnis S, Mahurin RK, Jerabek PA (2002) The functional neuroanatomy of the placebo effect. Am J Psych 159:728-737.

McGrath PJ, Stewart JW, Petkova E, Quitki FM, Amsterdam JD, Fawcett J, Reimherr FW, Rosenbaum JF, Beasley CM (2000) Predictors of relapse during fluoxetine continuation or maintenance treatment of major depression. J Clin Psychiatry 61:518-524.

Melzack R, Wall PD (1965) Pain mechanisms: a new theory. Science 150:971-979.

Miller EK, Cohen JD (2001) An integrative theory of prefrontal cortex function. Annu Rev Neurosci 24:167-202.

Moles A, Kieffer BL, D'Amato FR (2004) Deficit in attachment behavior in mice lacking the mu-opioid receptor gene. Science 304:1983-1986.
Montgomery SA (1996) Efficacy in long term treatment of depression. J Clin Psychiatry 57:24-30.

Nelson EE, Panksepp J (1998) Brain substrates of infant-mother attachment: contributions of opioids, oxytocin, and norepinephrine. Neurosci Biobehav Rev 22:437-452.

Ochsner KN, Bunge SA, Gross JJ, Gabrieli JD (2002) Rethinking feelings: an FMRI study of the cognitive regulation of emotion. J Cogn Neurosci 14:1215-1229.

Ochsner KN, Ray RD, Cooper JC, Robertson ER, Chopra S, Gabrieli JD, Gross JJ (2004) For better or for worse: neural systems supporting the cognitive down- and up-regulation of negative emotion. NeuroImage 23:483-499.

Pagnin D, de Queiroz V, Pini S, Cassano GB (2004) Efficacy of ECT in depression: a meta-analytic review. J ECT 20:13-20.

Petrovic P, Ingvar M (2002) Imaging cognitive modulation of pain processing. Pain 95:1-5.

Petrovic P, Kalso E, Petersson KM, Ingvar M (2002) Placebo and opioid analgesia-imaging a shared neuronal network. Science 295:1737-1740.

Petrovic P, Dietrich T, Fransson P, Andersson J, Carlsson K, Ingvar M (2005) Placebo in emotional processing —induced expectations of anxiety relief activate a generalized modulatory network. Neuron 46:957-969.

Phan KL, Fitzgerald DA, Nathan PJ, Moore GJ, Uhde TW, Tancer ME (2005) Neural substrates for voluntary suppression of negative affect: a functional magnetic resonance imaging study. Biol Psychiatry 57:210-219.

Phelps EA, O’Connor KJ, Gatenby JC, Gore JC, Grillon C, Davis M (2001) Activation of the left amygdala to a cognitive representation of fear. Nat Neurosci 4:437-441.

Pollo A, Torre E, Lopiano L, Rizzone M, Lanotte M, Cavanna A, Bergamasco B, Benedetti F (2002) Expectation modulates the response to subthalamic nucleus stimulation in Parkinsonian patients. NeuroReport 13:1383-1386.

Pollo A, Vighetti S, Rainero I, Benedetti F (2003) Placebo analgesia and the heart. Pain 102:125-133.

Posner MI (1980) Orienting of attention. Q J Exp Psychol 32:3-25.

Price DD, Milling LS, Kirsch I, Duff A, Montgomery GH, Nicholls SS (1999) An analysis of factors that contribute to the magnitude of placebo analgesia in an experimental paradigm. Pain 83:147-156.

Quitkin FM, Klein DF (2000) What conditions are necessary to assess antidepressant efficacy? Arch Gen Psychiatry 57:323-324.

Quitkin FRM, Rabkin JG, Gerald J, Davis JM, Klein DF (2000) Validity of clinical trails of antidepressants. Am J Psychiatry 157:327-337.

Rainville P, Duncan GH, Price DD, Carrier B, Bushnell MC (1997) Pain affect encoded in human anterior cingulate but not somatosensory cortex. Science 277:968-971.

Rizvi TA, Ennis M, Shipley MT (1992) Reciprocal connections between the medial preoptic area and the midbrain periaqueductal gray in rat: a WGAHRP and PHA-L study. J Comp Neurol 315:1-15.

Rubinstein M, Mogil JS, Japon M, Chan EC, Allen RG, Low MJ (1996) Absence of opioid stress-induced analgesia in mice lacking $\beta$-endorphin by site directed mutagenesis. Proc Natl Acad Sci USA 93:3995-4000.

Schlaepfer T, Strain E, Greenberg B, Preston K, Lancaster E, Bigelow G, Barta P, Pearlson G (1998) Site of opioid action in the human brain: mu and kappa agonists' subjective and cerebral blood flow effects. Am J Psychiatry 155:470-473.

Schultz W (2002) Getting formal with dopamine and reward. Neuron 36:241-263.

Schultz W, Tremblay L, Hollerman JR (2000) Reward processing in primate orbitofrontal cortex and basal ganglia. Cereb Cortex 10:272-278.

Singer T, Seymour B, O’Doherty J, Kaube H, Dolan RJ, Frith CD (2004) Empathy for pain involves the affective but not sensory components of pain. Science 303:1157-1162.

Smith Y, Zubieta J, Del Carmen M, Dannals R, Ravert H, Zacur H, Frost J (1998) Brain mu opioid receptor measurements by positron emission tomography in normal cycling women: relationship to LH pulsatility and gonadal steroid hormones. J Clin Endocrinol Metab 83:4498-4505.

Sora I, Takahashi N, Funada M, Ujike H, Revay RS, Donovan DM, Miner LL, Uhl GR (1997) Opiate receptor knockout mice define $\mu$ receptor roles in endogenous nociceptive responses and morphine-induced analgesia. Proc Natl Acad Sci USA 94:1544-1549.

Stewart JW, Quitkin FM, McGrath PJ, Amsterdam J, Fava M, Fawcett J, Reimherr F, Rosenbaum J, Beasley C, Roback P (1998) Use of pattern 
analysis to predict differential relapse on fluoxetine and placebo during continuation/maintenance treatment. Arch Gen Psychiatry 55:334-343.

Vaidya VA, Duman RS (2001) Depresssion-emerging insights from neurobiology. Br Med Bull 57:61-79.

Vase L, Robinson ME, Verne GN, Price DD (2003) The contributions of suggestion, desire, and expectation to placebo effects in irritable bowel syndrome patients. An empirical investigation. Pain 105:17-25.

Volkow ND, Wang G-J, Ma Y, Fowler JS, Zhu W, Maynard L, Telang F, Vaska P, Ding Y-S, Wong C, Swanson JM (2003) Expectation enhances the regional brain metabolic and the reinforcing effects of stimulants in cocaine abusers. J Neurosci 23:11461-11468.

Wager TD, Smith EE (2003) Neuroimaging studies of working memory: a meta-analysis. Cogn Affect Behav Neurosci 3:255-274.

Wager TD, Feldman Barrett L (2004) From affect to control: functional specialization of the insula in motivation and regulation. PsycExtra, available at http://www.psycinfo.com/psycextra/.

Wager TD, Phan KL, Liberzon I, Taylor SF (2003) Valence, gender, and lateralization of functional brain anatomy in emotion: a meta-analysis of findings from neuroimaging. NeuroImage 19:513-531.

Wager TD, Reading S, Jonides J (2004a) Neuroimaging studies of shifting attention: a meta-analysis. NeuroImage 22:1679-1693.

Wager TD, Rilling JK, Smith EE, Sokolik A, Casey KL, Davidson RJ, Kosslyn SM, Rose RM, Cohen JD (2004b) Placebo-induced changes in FMRI in the anticipation and experience of pain. Science 303:1162-1167.

Wagner KJ, Willoch F, Kochs EF, Siessmeier T, Tolle TR, Schwaiger M, Bartenstein P (2001) Dose-dependent regional cerebral blood flow changes during remifentanil infusion in humans: a positron emission tomography study. Anesthesiology 94:732-739.

Walsh BT, Seidman SN, Sysko R, Gould M (2002) Placebo response in stud- ies of major depression: variable, substantial, and growing. JAMA 287:1840-1847.

Watkins L, Mayer D (1982) Organization of endogenous opiate and nonopiate pain control systems. Science 216:1185-1192.

Zhang S, Tang JS, Yuan B, Jia H (1998) Inhibitory effects of electrical stimulation of ventrolateral orbital cortex on the rat jaw-opening reflex. Brain Res 813:359-366.

Zhang YQ, Tang JS, Yuan B, Jia H (1997) Inhibitory effects of electrically evoked activation of ventrolateral orbital cortex on the tail-flick reflex are mediated by periaqueductal gray in rats. Pain 72:127-135.

Zubieta JK, Smith Y, Bueller J, Xu Y, Kilbourn M, Meyer C, Koeppe R, Stohler C (2001) Regional mu opioid receptor regulation of sensory and affective dimensions of pain. Science 293:311-315.

Zubieta JK, Smith Y, Bueller J, Xu Y, Woike T, Kilbourn M, Meyer C, Koeppe $\mathrm{R}$, Stohler C (2002) $\mu$-Opioid receptor mediated antinociception differs in men and women. J Neurosci 22:5100-5107.

Zubieta JK, Ketter TA, Bueller JA, Xu Y, Kilbourn MR, Young EA, Koeppe RA (2003a) Regulation of human affective responses by anterior cingulate and limbic mu-opioid neurotransmission. Arch Gen Psychiatry 60:1145-1153.

Zubieta JK, Heitzeg MM, Smith YR, Bueller JA, Xu K, Xu Y, Koeppe RA, Stohler CS, Goldman D (2003b) COMT val158met genotype affects mu-opioid neurotransmitter responses to a pain stressor. Science 299:1240-1243.

Zubieta JK, Bueller JA, Jackson LR, Scott DJ, Xu Y, Koeppe RA, Stohler CS (2005a) Placebo effects mediated by endogenous opioid neurotransmission and $\mu$-opioid receptors. J Neurosci 25:7754-7762.

Zubieta JK, Yau WY, Scott DJ, Stohler CS (2005b) Belief or need? Accounting for individual variations in the neurochemistry of the placebo effect. Brain Behav Immun, in press. 